\title{
NASA Innovative Advanced Concepts
}

\author{
Ronald E. Turner, $\mathrm{PhD}^{1}$ \\ Analytic Services Inc, Falls Church, VA, 22041, USA \\ Jason Derleth $^{2}$ and Alvin Yew ${ }^{3}$ \\ NASA HQ, Washington DC, 20024, USA \\ and \\ Katherine M. Reilly ${ }^{4}$ \\ Bryce Space and Technology, Alexandria, VA 22314, USA
}

\begin{abstract}
The NASA Innovative Advanced Concepts (NIAC) Program nurtures visionary ideas that could transform future NASA missions with the creation of breakthroughs - radically better or entirely new aerospace concepts - while engaging America's innovators and entrepreneurs as partners in the journey. NIAC projects study innovative, technically credible, advanced concepts that could one day "Change the Possible" in aerospace. NIAC supports innovative research through two phases of study, both competitively awarded. The Phase I studies are for nine-month efforts to explore the overall viability of visionary concepts. Phase II studies further develop the most promising Phase I concepts for up to two years, and explore potential infusion options within NASA and beyond. Since 2011, NIAC has funded 136 studies (100 Phase I and 36 Phase II). Twenty studies funded to date have been directly related to human exploration, including habitats, environment control and radiation risk management. This paper provides an update to NIAC's history and current role including summary statistics about its selections, and notes the efforts directed toward human exploration.
\end{abstract}

\section{Nomenclature}

$\begin{array}{ll}\text { ESM } & =\text { Equivalent System Mass } \\ \text { ICES } & =\text { International Conference on Environmental Systems } \\ \text { IMLEO } & =\text { Initial Mass to Low Earth Orbit } \\ \text { NASA } & =\text { National Aeronautics and Space Administration } \\ \text { NIAC } & =\text { NASA Innovative Advanced Concepts (starting in 2011) } \\ \text { NIAC } & =\text { NASA Institute for Advanced Concepts (prior to 2011) } \\ \text { NSPIRES } & =\text { NASA Solicitation and Proposal Integrated Review and Evaluation System } \\ \text { USRA } & =\text { Universities Space Research Association } \\ \text { NEC } & \text { NIAC External Council } \\ \text { SSO } & \text { Source Selection Officer } \\ \text { STEM } & =\text { Science, Technology, Engineering and Mathematics } \\ \text { STP } & =\text { Space Technology Program } \\ \text { STMD } & =\text { Space Technology Mission Directorate }\end{array}$

\section{Introduction}

$\mathrm{N}$ IAC is unique! It is a program that values both technical acumen and imagination, inspired by curiosity and the quest for knowledge. We encourage innovators to be creative and attempt great leaps forward in aerospace

\footnotetext{
${ }^{1}$ Distinguished Analyst, Analytic Services Inc, Suite N-5000 5275 Leesburg Pike, Falls Church, VA 22041.

${ }^{2}$ Program Executive, NIAC \& CIF, STMD / 6X53, 300 E Street SW.

${ }^{3}$ Program Manager, NIAC, STMD / 6X58, 300 E Street SW.

${ }^{4}$ Strategic Partnership Manager, NIAC, STMD, 300 E Street SW.
} 
endeavors. NIAC calls for visionary concepts that may be expansive in scope, may inspire new classes of enabling technologies, and may feature disciplines outside of the mainstream aerospace fields. A good NIAC concept seeks to "Change the Possible" or offer revolutionary improvement. This paper provides an update to Turner, et al, $2013^{1}$.

\section{NIAC Goals and Objectives}

NIAC supports innovative research through two phases of study. The Phase I awards are nine-month efforts to explore the overall feasibility and viability of visionary concepts. The follow-on Phase II awards further develop the most promising Phase I concepts for up to two years, and explore potential infusion options within NASA and beyond.

A NIAC concept must be an aerospace architecture that is innovative, offers high potential impact, is credible and reasonable, and is examined in a mission context.

Aerospace includes activities related to space and aeronautics. An architecture includes multiple systems, and a concept of how they are used together to achieve mission goals. A mission is a plan to achieve one or more clear objectives (e.g., advancing exploration, science, aerospace operations), to benefit NASA or the larger aerospace community.

NIAC concepts must break new ground, changing the conversation about future possibilities. They could enable an entirely new mission, greatly improve execution of current missions, or offer a great leap in capabilities. Selected studies have demonstrated there are benefits to conducting the study now, even if the ultimate vision is far-term or high risk.

The underlying technologies or concepts and the implementation in a mission must be technically sound - based on solid scientific/engineering principles. Generally a NIAC concept is based on new technology, but it could be based on existing technology applied to a mission in significantly new and innovative ways, perhaps by adapting a technology typically applied in a non-aerospace domain into a NASA context.

A key feature of NIAC studies is they assess the concept in a space or aeronautics mission context - the main focus is determining feasibility and comparing properties and performance with those of currently conceived missions or concepts. This is more important than detailed analysis of the underlying phenomena or technology. Concepts that may support multiple missions must feature detailed analysis of at least one candidate mission application. The mission context need not be a current or planned NASA mission. Rather, any aerospace mission (previously considered or hypothetical) may be selected, as long as it could reasonably be within NASA's domain. The reason NIAC studies focus on missions, instead of directly developing a key technology, is NAIC studies are intended to show that it would be worth NASA's efforts to further develop an innovative idea. Investment in the underlying technology or "secret sauce" would come after the NIAC study demonstrates feasibility.

Mission context is often a challenge for technologists who traditionally focus on subsystems or narrow aspects of a larger mission. An Environment Control and Life Support System (ECLSS) is a good example. For NIAC to choose a study of an improved ECLSS, the study must first compare the benefits of the new system to competitive concepts (state of the art, already under development, or previously considered for implementation). But it must also show, in a quantifiable way, that it would substantially reduce mission cost: perhaps by reduced total "initial mass in low Earth orbit" (IMLEO) compared to some reference mission or by estimating the Equivalent System Mass (ESM), which assigns a "mass budget" to subsystem power and volume. Such metrics would illustrate that while an approach may reduce the consumable mass required, it does not in turn require so much power or thermal control (and the associated mass to provide them) as to swamp the consumable mass reduction.

NIAC Phase I studies are approximately nine months for preliminary concept investigation. Initially, the studies were funded at $\$ 100 \mathrm{~K}$, but starting with the pending Fiscal Year 2017 awards (estimated to begin in May, 2017) the award total will increase to $\$ 125 \mathrm{~K}$.

NIAC Phase II awards (approximately two years and \$500K) continue the exploration and development of revolutionary advanced concepts that have been initiated through a NIAC Phase I award. The primary goal of the Phase II effort is to study major feasibility issues associated with cost, performance, development time and key technologies. These results are aimed at providing a sound basis for NASA to consider the concept for further development and a future mission, substantiated with a description of applicable scientific and technical disciplines necessary for development.

Since Phase II studies are nominally two years long, there is a Midterm Review at the end of the first year. Continued funding for the second year is contingent on successful demonstration of progress at the Midterm Review. To aid in the future infusion of the concept into NASA, technical representatives from possible target organizations (within and outside of NASA) are invited to the Review. 


\section{NIAC History}

\section{A. Background}

A general background of NIAC, focused on the earlier NASA Institute of Advanced Concepts and its eventual transition to the NASA Advanced Concepts Program is covered in Turner, et al, 2013. NASA has always sought out innovative ways to push the boundaries of technology and exploration. Investment in futuristic, innovative research has historically benefitted the nation as a whole on a far-reaching basis - up to and including generating entire new industries.

The NASA Institute of Advanced Concepts (known widely as "NIAC" but referred to herein as "the Institute" to avoid confusion with the current program), was led by Dr. Robert Cassanova and started in 1998 under a contract to Universities Space Research Association. The Institute continued until its termination in August 2007. It was run as a virtual institute, which, befitting its name was an innovative operational construct at the time. During its nine years of operation, the Institute received 1309 proposals and awarded 126 Phase I studies and 42 Phase II studies².

The Institute's legacy may well be summed up by its signature quote, attributed to Dr. Robert Cassanova and Sharon Garrison, the NASA Contracting Officer's Technical Representative: "Don't let your preoccupation with reality stifle your imagination."

The Institute's 2007 termination occurred in a period when NASA was strongly focused on planning for a return to the Moon. In 2008, Congress directed NASA to commission a National Research Council (NRC) study to evaluate the Institute's performance and to make recommendations concerning whether the Institute should be reinstated. If so, the NRC was also asked to suggest changes that could increase its effectiveness.

The NRC responded with a report in 2009, "Fostering Visions of the Future"3 that was highly supportive of the Institute, and recommended that NASA reinstate a NIAC-like entity, but suggested a few changes as well. The NRC endorsed the Institute's vision, scope, and selection process. The most substantial change was to open the process to NASA researchers.

In 2010, the NASA Chief Technologist invited Dr. Jay Falker to NASA HQ to address the NRC recommendations about NIAC. Dr. Falker proceeded to establish the NASA Innovative Advanced Concepts (NIAC) program, hosted by the Space Technology Program in the Office of the Chief Technologist, in late 2010, early 2011. The program name was modified slightly to reflect the fact that it would no longer be a purely external institute. But the acronym NIAC was preserved to send a clear signal that the new program would be true to the goals and ideals of the Institute.

Figure 1 is a NIAC organization chart. In 2012 NASA more formally separated the Office of the Chief Technologist from the Space Technology Program, and in 2013 it elevated the Space Technology Program to Directorate level: The Space Technology Mission Directorate (STMD). Today, NIAC remains within STMD and continues its role as the entry point for innovative concepts that may someday "change the possible" in the words of its initial Program Executive, Dr. Jay Falker. Dr. Falker was promoted in 2015 to lead STMD's Early Stage Innovation portfolio, which includes NIAC. Jason Derleth, initially the NIAC Program Manager, became the Program Executive. Dr. Alvin Yew was named the Program Manager. Dr. Ronald Turner and Kathy Reilly continued in the roles they had since 2012. Principal Investigators of funded NIAC studies are designated "NIAC Fellows" and are considered a part of the NIAC organization, even after their funded studies have concluded. 


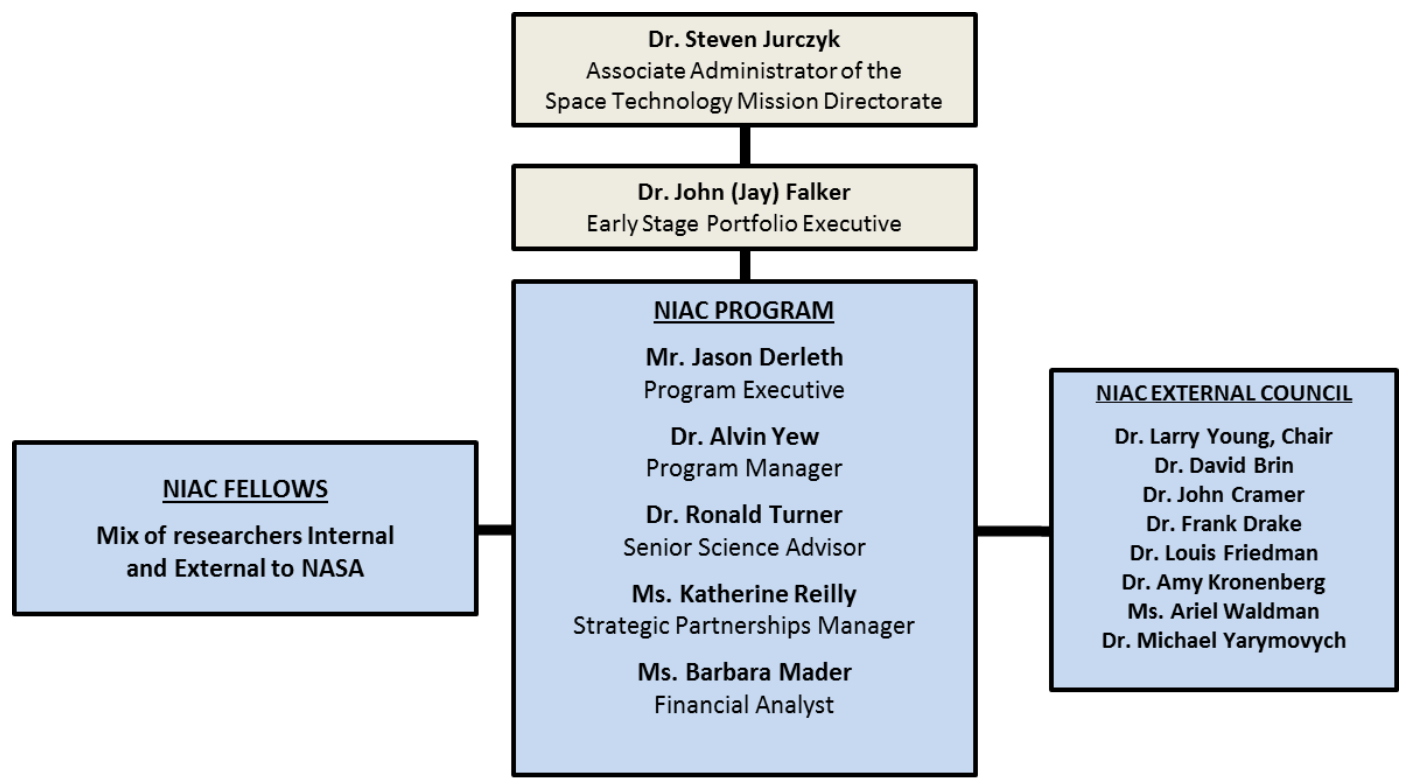

Figure 1. NIAC Organization Chart. NIAC is managed out of NASA Headquarters. The Program Manager is at NASA Goddard Space Flight Center

Note that NIAC retains a feature of the original Institute, an External Council, consisting of distinguished individuals whose role is to assess how well NIAC is meeting its vision and goals and to make recommendations to the NIAC Program Executive. The NIAC External Council (NEC) attends NIAC's public symposia and meets formally after each symposium to discuss any issues and to provide feedback. Professor Larry Young has been the NEC Chair since 2015.

\section{NIAC Study Selection Process}

\section{A. Phase I Proposal Evaluation Process}

NIAC studies are selected by merit as determined by a thorough peer review process. Anyone is eligible to submit a NIAC Phase I proposal (while NASA can fund only US organizations, foreign entities may propose but if selected the study will be conducted on a "no exchange of funds" basis). The Phase I and Phase II solicitation process is shown in Figure 2.
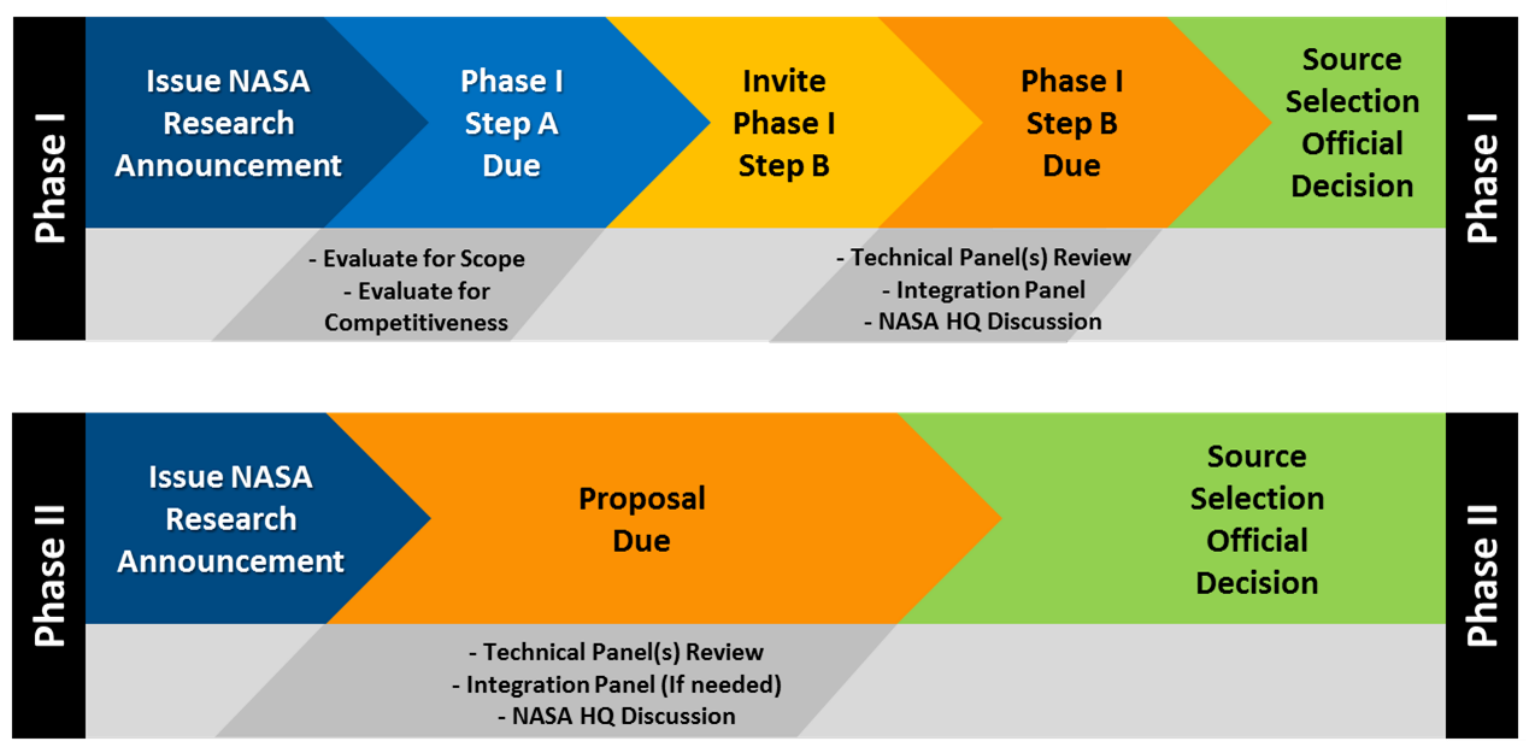

Figure 2. Phase I and Phase II solicitation Process 
NIAC Phase I selection begins with the release of a call for proposals through the NASA Solicitation and Proposal Integrated Review and Evaluation System (NSPIRES) (http://nspires.nasaprs.com). Scope is a tricky subject for NIAC, so the Program Office uses a two-step process to avoid wasting the proposers, and subsequently the reviewers, time. Step A proposals are very brief descriptions of the concept. The NIAC Program Office reviews the Step A proposals and invites the most promising of the eligible concepts to submit a more thorough Step B proposal.

The full scope of NIAC Phase I concepts was described earlier. Other programs at NASA have the responsibility to explore and develop new technologies, materials, or subsystems. A continuing challenge in the NIAC Program is to articulate the unique niche that NIAC fills: the opportunity to explore bold new ideas that may fundamentally change the way NASA embarks on future missions, by looking at concepts in mission context. In line with the approach used by the Institute, to further clarify what NIAC is looking for in a study, NIAC solicitations also note what the program is not looking for. Table 1 is the list as published in the 2017 NIAC Call for Proposals. Out of scope examples, which are not considered for award, include narrowly focused technology studies, proposals for scientific studies, and broad literature reviews of advanced technology or approaches.

- Not an aerospace architecture. Fails to sufficiently address NASA goals or potential space or aeronautics benefits.

- Proposed concept is unclear or not adequately articulated. It fails to identify or propose to study a specific innovative concept. NIAC does not fund studies that identify a difficult challenge coupled with a plan for a thorough literature search or trade off study of known alternative concepts.

- No mission context. The mission context is missing or insufficiently described.

- Previously explored. Does not identify a new factor that substantially differentiates the proposal from prior efforts.

- Incremental. Proposes typical next steps or aims at only modest improvement, rather than investigating far-term or high-risk "breakthrough" concepts.

- Not technically credible. Conflicts with established physics or engineering principles, without acknowledging this and offering a sufficiently plausible defense.

- Not programmatically credible. No reasonable path to implementation, without acknowledging the barriers (e.g., requiring unrealistic budgets or policy changes) and offering a sufficiently plausible approach.

- The proposal is too narrowly focused on technology or subsystems development of smaller scope (e.g., components, instruments, materials) without sufficient evidence of incorporation into a mission context. While some focused work may be appropriate to establish the credibility of the underlying technology, a NIAC study must also include a detailed mission analysis.

- The proposal is too narrowly focused on science experiments (e.g., laboratory characterization, field work) without sufficient evidence of incorporation into a mission context. While a NIAC study may involve such efforts, it must also include a detailed mission analysis.

- The proposal is too narrowly focused on the development of tools or processes (e.g., improve design, decision-making, algorithm development) without sufficient evidence of incorporation into a mission context. While these are often beneficial products of a study, a NIAC study must also include a detailed mission analysis.

Table 1. In line with the NIAC goal to foster truly revolutionary concepts, calls for proposals identify types of studies that are outside NIAC's scope. Proposals that fit into these categories are not considered for award.

There is great enthusiasm within the aerospace community for exploring revolutionary ideas. As a result, there is a tremendous response to NIAC's calls for studies. Since NIAC can only fund a fraction of the hundreds of proposed concepts, the first step in the evaluation process is a determination by the Program Office whether each proposal meets NIAC's scope, as explained in the solicitations. Proposals that fail are assigned a primary, and in some cases also a secondary, reason why it was determined to be out of scope. Table 2 shows the frequency with which a Step A proposal failed to be deemed in scope for FY 13 through FY 16. For the past few years, the chief reasons have been that the concept was either seen as incremental, or the proposed study did not adequately put the innovative idea in a mission concept, or the proposal was too heavily focused on an underlying technology or research. 


\begin{tabular}{|l|ccccc|}
\hline \multicolumn{5}{|c|}{$\begin{array}{c}\text { Combined Reasons for Out of Scope } \\
\text { By percentage of occurrences }\end{array}$} \\
\hline Out of Scope Reason & FY 13 & FY 14 & FY 15 & FY 16 \\
\hline Incremental & 19.6 & 20.9 & 21.2 & 24.3 \\
Unclear mission application & $*$ & 19.8 & 26.0 & 22.6 \\
Narrowly focused technology & 28.7 & 19.0 & 12.5 & 14.7 \\
Experiment or research & 12.3 & 10.6 & 8.7 & 10.2 \\
Not technically credible & 5.6 & 2.2 & 6.3 & 9.6 \\
Previously studied & 11.9 & 16.8 & 12.0 & 6.8 \\
Unclear concept & 13.7 & 5.1 & 3.4 & 6.8 \\
Tool or process & 3.4 & 3.3 & 4.8 & 4.0 \\
Not programmatically credible & 3.6 & 1.1 & 3.8 & 0.6 \\
Not aerospace & 1.2 & 1.1 & 1.4 & 0.6 \\
\hline
\end{tabular}

Table 2 This table shows the percentage of times that each of the out of scope criteria was invoked as a Primary or Secondary reason for screening out a proposal. In FY 13 "Unclear Concept" and "Unclear Mission Application" were combined in one category.

A further screening of the remaining Step A proposals looks at the potential competitiveness of the concept, which is based on the proposed concept's potential impact if fully successful and the clarity with which the proposal describes the essential elements of the concept and addresses the concept's plausibility and feasibility. Principal Investigators of the highest rated eligible proposals are invited to submit a more complete Step B proposal.

NIAC Phase I Step B proposals are assigned to Technical Panels for review. The number of panels is determined by the number and technical mix of the proposals: in FY 12, there were five technical panels, from FY 13 on, there has been three technical panels and one follow-on Integration panel. The technical panels are charged to evaluate the proposals against the review criteria. In FY 17 these criteria, as published in the NASA Research Announcement, were:

\section{- Innovation (25 percent)}

- The concept is unexplored or provides sufficiently new approaches to successfully execute the proposed mission. The underlying architecture is technically sound, with at least one plausible implementation path. Preliminary justification and "back of the envelope" approximations show credibility. However, unknowns remain that are not readily determined, thereby warranting further study. The concept must thoroughly describe a mission and its architecture. Novel capabilities should be included and must be contextualized by a mission to show where and how it can be implemented.

\section{- Potential Impact of the Concept (30 percent)}

- If successful, the concept will enable wholly new missions, offer a significant advantage to previously studied work, or provide a great leap in capabilities for NASA or the greater aerospace community. The concept has the potential to generate enthusiasm for a mission and potential to build advocacy to support it within NASA or in the greater aerospace community.

\section{- Technical Approach (25 percent)}

- Work plan demonstrates understanding of major issues, proposing a logical, strategic, and judicious course of study to address significant unknowns, barriers, and necessary technology development. There is a plan to evaluate alternative approaches to the concept and how new factors substantially differentiate it from prior efforts. Work plan includes analysis in one specific mission that involves the development of its architecture and system trade considerations. Team members are sufficiently qualified and adequate resources are identified to complete the study as proposed. The study timeline is commensurate with the scope of the proposed budget. There is sufficient budget for labor, materials and supplies, mandatory travel, etc. to complete the study.

\section{- Other Benefits of the Study (20 percent)}

$\circ$ As a result of performing the study, there are notable scientific, engineering, or creative benefits that contribute to its specific field, even if the concept is shown infeasible. There are wider benefits of the study. For example but not limited to, engaging the public, making a contribution to the national economy, or producing potential non-aerospace spinoffs. 
The fourth criterion deserves some elaboration, as it is unique to the NIAC process. In keeping with NIAC's goal to "change the possible" it is important that the outcome of the study itself have value, before the concept would have time to be implemented. This has both positive and negative aspects. Positive influences would include significantly changing the dialogue about a proposed concept... would the study focus attention on the idea, would it lead others to consider the approach more critically? Other positive impacts may include the possibility of leading to the start of immediate spinoffs, perhaps outside of the aerospace community. On the negative side, a proposal would be downgraded if it were judged that the study would not contribute substantially to a body of existing studies of closely related concepts. If an idea is innovative in the sense that it has promise yet has not been implemented, but a large body of work has been done to explore that concept, then further study would have less benefit.

The technical panels consider the proposals and submit a technical evaluation against the criteria resulting in an overall technical score. They then submit a final overall recommendation to NASA: how strongly would they recommend funding the proposed study? This advice is guided by the technical scores, but need not be constrained by them. While rare, a panel may issue a recommendation that is higher or lower than the technical scores would suggest, provided with an accompanying justification.

The final Technical Panel evaluation forms the basis of all further deliberation and discussion, and also provides the formal evaluation feedback to the proposers (in most cases exactly as received; in rare cases subsequent discussion adds a further notable comment). No subsequent step ever changes any technical review. However, there are additional steps in the selection process, to include:

- An Integration Panel - needed when NIAC has multiple Technical Review Panels, in Phase I. This looks across the evaluations from each, and if needed recommends shifts in the final recommendations only. This is needed if some proposals appear to be out of family in terms of merit or quality from the Technical Review, compared to the others that received similar ratings. The Integration Panel also takes the first look at the final list as a portfolio, and votes to recommend funding order of the highest rated proposals.

- HQ Discussion/Selection - first, NIAC checks with other NASA programs for potential duplication or synergy. NIAC seeks comments only, not further technical review. These inputs may or may not affect the final recommendation order sent to the Source Selection Officer (for NIAC this is the STMD Associate Administrator, or his Deputy if designated), but all Technical Panel scores are presented, unchanged. The Selection Officer also considers political factors and overall STMD portfolio balance, and makes the final selection. Technically, all of NIAC's review inputs are merely advisory — but to date NASA has demonstrated confidence in and respect for the NIAC review process, and implemented very few changes in final awards.

\section{B. Phase II Proposal Evaluation Process}

NIAC Phase II selection also begins with the release of a call for proposals through NSPIRES. However, the eligibility is substantially different. Only Fellows who have completed a Phase I study may submit a Phase II proposal, and the study must be substantially based on the Phase I study results. Because of its termination, Fellows of the Institute may also submit Phase II proposals if the concept was not selected for Phase II or if it was selected but the Phase II study was cancelled before it could be completed. Again, the concept must be substantially based on the prior Phase I study.

The proposed studies are submitted to one or more technical panels for review. Since these concepts have already been selected against the NIAC scope criteria, and since the studies are aimed at providing a sound basis for NASA to consider the concept for further development and a future mission, the evaluation criteria are different from that of the Phase I studies. As posted in the FY 17 Phase II NASA Research Announcement, the evaluation criteria are similar to the Phase I criteria, but adjusted to reflect the lessons that should have been learned in Phase I:

\section{- Innovation (20 percent)}

○ The concept continues to demonstrate unexplored and exciting aspects of value to investigate over the Phase I study. Analysis completed in Phase I is credible. However, unknowns remain that are not readily determined, thereby warranting further study. The concept is thoroughly described in a mission and its architecture. Novel capabilities are included and contextualized by a mission to show where and how it can be implemented.

- Potential Impact of the Concept (30 percent)

o If successful, the concept will enable wholly new missions, offer a significant advantage to previously studied work, or provide a great leap in capabilities for NASA or the greater aerospace community. Based on results from the Phase I study, the concept continues to generate enthusiasm for a mission and potential to build advocacy to support it within NASA or in the greater aerospace community. 


\section{- Technical Approach (30 percent)}

○ Work plan demonstrates understanding of major issues, proposing a logical, strategic, and judicious course of study to address significant unknowns, barriers, and necessary technology development. Proposed research objectives build on Phase I findings. Team members are sufficiently qualified and adequate resources are identified to complete the study as proposed. The study timeline is commensurate with the scope of the proposed budget. There is sufficient budget for labor, materials and supplies, mandatory travel, etc. to complete the study. A plan to develop a technology roadmap has been adequately described and there is a mechanism for identifying the enabling technologies, which culminates in a feasible implementation of the concept.

\section{- Other Benefits of the Study (20 percent)}

$\circ$ As a result of performing the study, there are notable scientific, engineering, or creative benefits that contribute to its specific field, even if the concept is shown infeasible. The proposed study and its products are likely to significantly advance NASA's understanding of concept feasibility and benefit. There are wider benefits of the study. For example but not limited to, engaging the public, making a contribution to the national economy, or producing potential non-aerospace spinoffs.

The Phase II Technical Panel products are similar to those of Phase I Technical Panels: detailed evaluations and advice on funding priority. There has only been one Technical Panel each year, so there has been no need for an Integration Panel. The Phase II Technical Panel is followed by steps similar to the Phase I process.

\section{Overview of Funded Projects}

\section{A. General Statistics}

Since 2011, NIAC has funded 136 studies (100 Phase I and 36 Phase II). The distribution of awards by organization type is shown in Table 3. It is anticipated that fifteen to seventeen new Phase I studies and five to seven new Phase II studies will be selected in March 2017. Table 3 shows the breakdown of total NIAC awards (Phase I and Phase II) through March 2017 by Fiscal Year and by organization type. Figure 3 shows the approximate dollar total awarded (at $\$ 100 \mathrm{~K}$ for each Phase I and $\$ 500 \mathrm{~K}$ for each Phase II) by organization type for Phase I, Phase II and total. They are grouped by the Principal Investigator's (the Fellow's) organization, so the dollar distribution does not reflect funds that may have been subcontracted or otherwise allocated to other organizations. The category "NASA" includes all NASA Centers, including the Jet Propulsion Laboratory. The category "Industry/Other" includes a variety of organization types, including large and small businesses, not-for-profit and research institutes, etc. Figure 4 shows how NIAC awards have been distributed throughout the United States (as of February 2017): 22 states and the District of Columbia are home to one or more NIAC Fellows.

\begin{tabular}{|r|c|ccccc|c|}
\hline \multicolumn{7}{|c|}{ Number of Awards } \\
\hline Phase I & FY 11 & FY 12 & FY 13 & FY 14 & FY 15 & FY 16 & Totals \\
\hline NASA & 11 & 8 & 5 & 6 & 4 & 6 & 40 \\
Academia & 10 & 3 & 3 & 2 & 8 & 2 & 28 \\
Other & 9 & 7 & 4 & 4 & 3 & 5 & 32 \\
\hline Totals: & 30 & 18 & 12 & 12 & 15 & 13 & 100 \\
\hline
\end{tabular}

\begin{tabular}{|r|c|cccccc|}
\hline \multicolumn{7}{|c|}{ Number of Awards } \\
\hline Phase II & FY 11* & FY 12 & FY 13 & FY 14 & FY 15 & FY 16 & Totals \\
\hline NASA & 0 & 3 & 2 & 1 & 3 & 1 & 10 \\
Academia & 0 & 3 & 2 & 3 & 3 & 5 & 16 \\
Other & 0 & 4 & 2 & 1 & 1 & 2 & 10 \\
\hline Totals: & 0 & 10 & 6 & 5 & 7 & 8 & 36 \\
\hline
\end{tabular}

Table 3. A breakdown of Phase I and Phase II awards by organization and Fiscal Year 


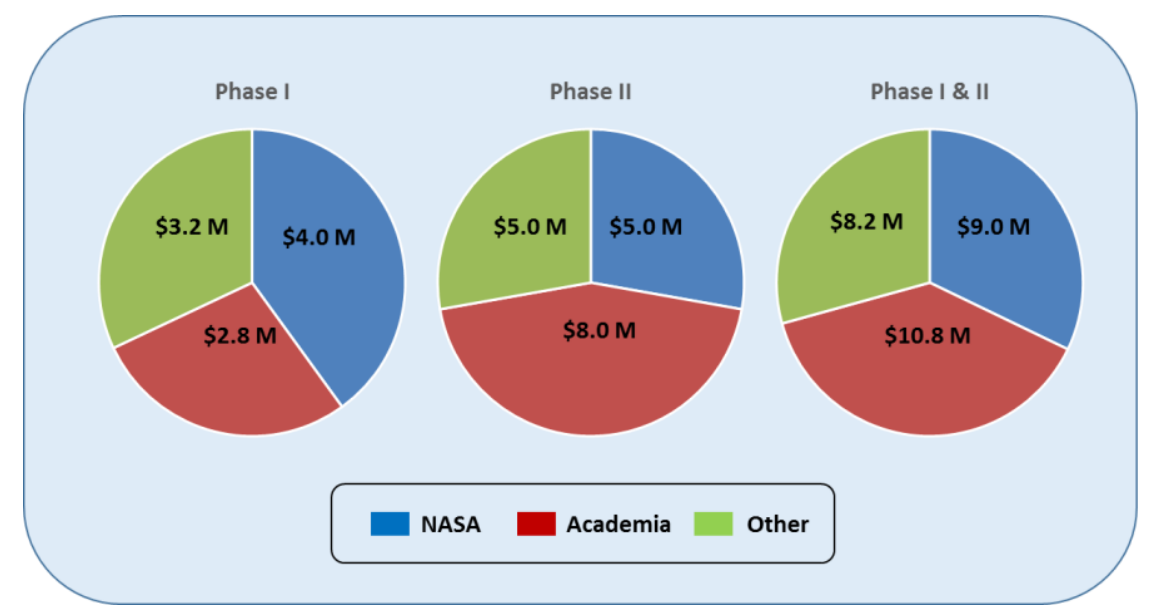

Figure 3. A breakdown of total NIAC awards by dollar amount (see text for additional details).

\section{Funding Innovation across the Nation}

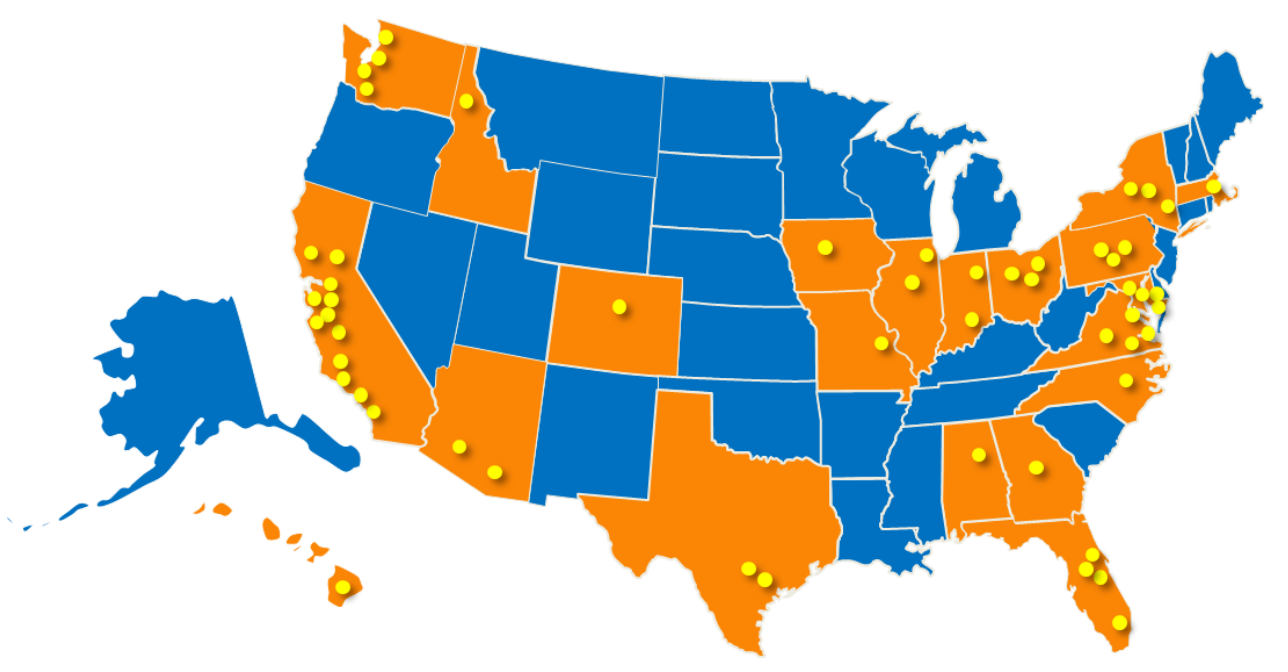

Figure 4. Locations of NIAC Fellows.

A full list of NIAC funded studies, along with links to final reports and symposium presentations, is available on the NIAC website: http://www.nasa.gov/directorates/spacetech/niac/NIAC funded studies.html

\section{B. Technical Areas represented in NIAC Studies}

NIAC is open to any technical area that is relevant to NASA, and NIAC has funded concepts that cover almost all of NASA. Figure 5 and Table 4 give a flavor of what areas have been studied in the 100 Phase I studies, and the 36 Phase II studies. Figure 5 shows the number of Phase I, Phase II, and total studies in five broad categories. Table 4 breaks these categories down further into subcategories. Since NIAC studies are sometimes inherently multidiscipline and put the underlying concept in a mission context, it is sometimes difficult to place a concept into a specific "box" to say it is deep space transportation, for example, if it includes multiple disciplines and objectives.

- Transportation (Earth to Orbit, In Space, Entry/Descent/Landing, Infrastructure, and Aeronautics)

- Human Exploration (Environment Control, Radiation Mitigation, Habitats, Infrastructure) 
- Robotics (Mobility, Sample Collection)

- Science (Astronomy, Planetary, Heliophysics, Earth Science)

- Other (Navigation, Power, Communications, Structures, Asteroid/Orbital Debris Mitigation)

Table 5 is a listing of the studies most relevant to the International Conference on Environmental Systems (ICES) conference.

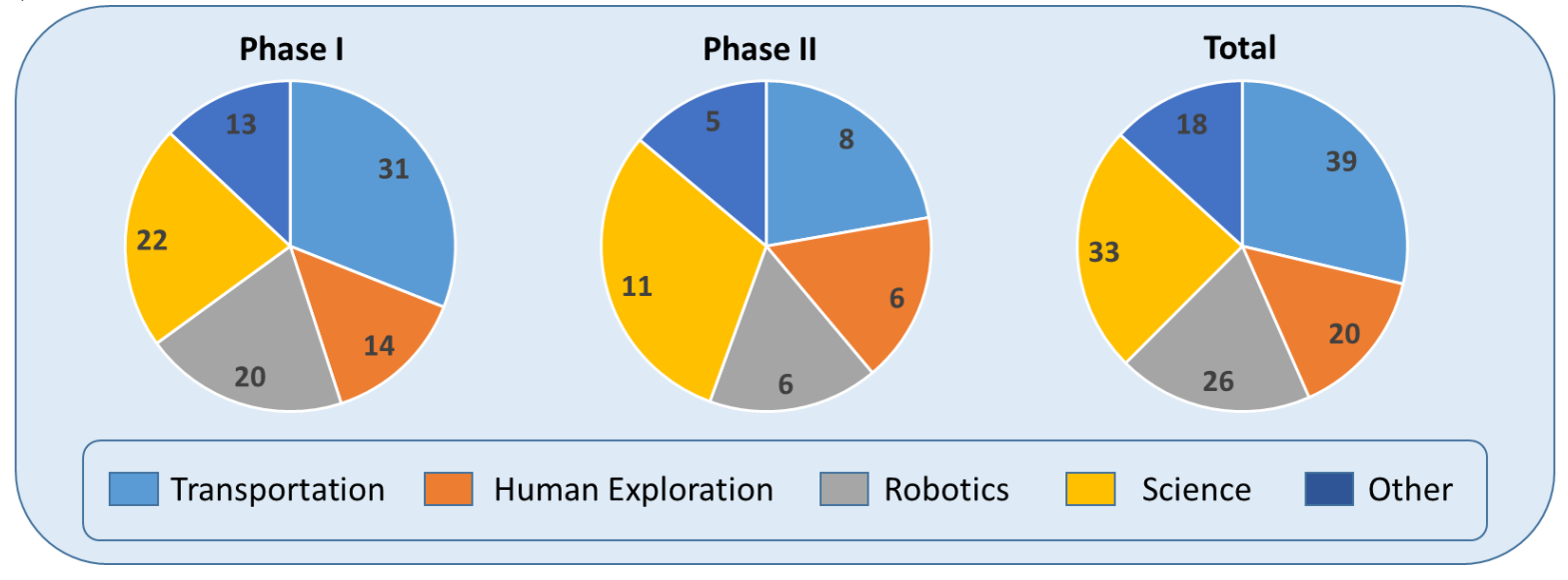

Figure 5. NIAC Funded Studies by broad technical areas

\begin{tabular}{|c|c|c|c|c|c|}
\hline Area & \multicolumn{5}{|c|}{ Transportation } \\
\hline Discipline & Earth to Orbit & In-Space & $\begin{array}{l}\text { Entry, Descent } \\
\text { and Landing }\end{array}$ & $\begin{array}{l}\text { Transportation } \\
\text { Infrastructure }\end{array}$ & Aeronautics \\
\hline Phase I & 0 & 16 & 3 & 9 & 3 \\
\hline Phase II & 0 & 5 & 1 & 1 & 1 \\
\hline Total & 0 & 21 & 4 & 10 & 4 \\
\hline Area & \multicolumn{5}{|c|}{ Human Space Exploration } \\
\hline Discipline & $\begin{array}{l}\text { Environment } \\
\text { Control and } \\
\text { Life Support } \\
\text { Systems }\end{array}$ & $\begin{array}{l}\text { Radiation Risk } \\
\text { Mitigation }\end{array}$ & Habitat & $\begin{array}{l}\text { Human Base } \\
\text { Infrastructure }\end{array}$ & \\
\hline Phase I & 4 & 3 & 1 & 6 & \\
\hline Phase II & 1 & 1 & 1 & 3 & \\
\hline Total & 5 & 4 & 2 & 9 & \\
\hline Area & \multicolumn{5}{|c|}{ Robotic Exploration } \\
\hline Discipline & Mobility & $\begin{array}{c}\text { Sample } \\
\text { Collection }\end{array}$ & & & \\
\hline Phase I & 17 & 3 & & & \\
\hline Phase II & 5 & 1 & & & \\
\hline Total & 22 & 4 & & & \\
\hline Area & \multicolumn{5}{|c|}{ Science } \\
\hline Discipline & Astronomy & Planetary & Heliophysics & Earth & \\
\hline Phase I & 10 & 11 & 0 & 1 & \\
\hline Phase II & 6 & 5 & 0 & 0 & \\
\hline Total & 16 & 16 & 0 & 1 & \\
\hline Area & \multicolumn{5}{|c|}{ Other } \\
\hline Discipline & Navigation & Power & Communications & Structures & $\begin{array}{c}\text { Asteroid and } \\
\text { Debris Mitigation }\end{array}$ \\
\hline Phase I & 1 & 5 & 1 & 2 & 3 \\
\hline Phase II & 0 & 2 & 0 & 2 & 1 \\
\hline Total & 1 & 7 & 1 & 4 & 4 \\
\hline
\end{tabular}

Table 4. NIAC Funded Studies characterized in more detailed technical areas 


\begin{tabular}{|c|c|c|c|}
\hline \multicolumn{4}{|c|}{ NIAC Studies relevant to Human Space Exploration } \\
\hline $\begin{array}{c}\text { Fiscal } \\
\text { Year } \\
\text { Selected }\end{array}$ & $\begin{array}{l}\text { Phase } \\
\text { I or II }\end{array}$ & $\begin{array}{c}\text { Principal } \\
\text { Investigator } \\
\text { (Fellow) }\end{array}$ & ( \\
\hline FY 11 & 1 & Duda, Kevin & Variable Vector Countermeasure Suit (V2Suit) for Space Habitation and Exploration \\
\hline FY 11 & 1 & $\begin{array}{l}\text { Khoshnevis, } \\
\text { Behrokh }\end{array}$ & Contour Crafting Simulation Plan for Lunar Settlement Infrastructure Build-Up \\
\hline FY 11 & 1 & Thibeault, Sheila & $\begin{array}{l}\text { Radiation Shielding Materials Containing Hydrogen, Boron, and Nitrogen: Systematic } \\
\text { Computational and Experimental Study }\end{array}$ \\
\hline FY 11 & 1 & Tripathi, Ram & $\begin{array}{l}\text { Meeting the Grand Challenge of Protecting Astronaut's Health: Electrostatic Active Space } \\
\text { Radiation Shielding for Deep Space Missions }\end{array}$ \\
\hline FY 11 & I & Westover, Shayne & $\begin{array}{l}\text { Radiation Protection and Architecture Utilizing High Temperature Superconducting } \\
\text { Magnets }\end{array}$ \\
\hline FY 12 & II & Duda, Kevin & Variable Vector Countermeasure Suit (V2Suit) for Space Habitation and Exploration \\
\hline FY 12 & 1 & Flynn, Michael & Water Walls: Highly Reliable and Massively Redundant Life Support Architecture \\
\hline FY 12 & 1 & Gellett, Wayne & Solid State Air Purification System \\
\hline FY 12 & II & $\begin{array}{l}\text { Khoshnevis, } \\
\text { Behrokh }\end{array}$ & ISRU-Based Robotic Construction Technologies for Lunar and Martian Infrastructures \\
\hline FY 12 & II & Westover, Shayne & $\begin{array}{l}\text { Radiation Protection and Architecture Utilizing High Temperature Superconducting } \\
\text { Magnets }\end{array}$ \\
\hline FY 13 & 1 & Bradford, John & Torpor Inducing Transfer Habitat For Human Stasis To Mars \\
\hline FY 13 & 1 & $\begin{array}{l}\text { Longman. } \\
\text { Anthony }\end{array}$ & Growth Adapted Tensegrity Structures - A New Calculus for the Space Economy \\
\hline FY 13 & 1 & Rothschild, Lynn & Biomaterials out of thin air: in situ, on-demand printing of advanced biocomposites \\
\hline FY 14 & 1 & Boland, Eugene & Mars Ecopoiesis Test Bed \\
\hline FY 14 & 1 & Chen, Bin & $\begin{array}{l}\text { 3D Photocatalytic Air Processor for Dramatic Reduction of Life Support Mass \& } \\
\text { Complexity }\end{array}$ \\
\hline FY 15 & II & Chen, Bin & $\begin{array}{l}\text { 3D Photocatalytic Air Processor for Dramatic Reduction of Life Support Mass and } \\
\text { Complexity }\end{array}$ \\
\hline FY 15 & I & Graf, John & Thirsty Walls - A new paradigm for air revitalization in life support \\
\hline FY 16 & II & Bradford, John & Advancing Torpor Inducing Transfer Habitats for Human Stasis to Mars \\
\hline FY 16 & 1 & Rothschild, Lynn & $\begin{array}{l}\text { Urban biomining meets printable electronics: end-to-end destination biological recycling } \\
\text { and reprinting }\end{array}$ \\
\hline FY 16 & II & Skelton, Robert & Tensegrity Approaches to In-Space Construction of a 1g Growable Habitat \\
\hline
\end{tabular}

Table 5. NIAC Funded Studies Relevant to the International Conference on Environmental Systems

Three NIAC Phase I studies were aimed at mitigating the radiation risk. Westover examined an innovative magnetic active shielding concept which went on to a Phase II study. Thibault proposed advanced composite 
materials that had high hydrogen content, while Tripathi studied an active electrostatic field to deflect high energy radiation.

Four NIAC Phase I studies (Flynn, Gellet, Graf, and Chen) looked at ways to improve Environmental Control and Life Support Systems. Chen was selected to continue with a Phase II study.

One NIAC Phase I study by Longman examined a new way to build space habitats in a manner that allowed for continued expansion, from an initial size hosting around ten astronauts, to a full scale colony habitat supporting hundreds of inhabitants. This study went on to a Phase II study led by Skelton.

Six NIAC Phase I studies examined ways to support humans in space or in a base. One, by Duda, which went on to Phase II, looked at a suit that could serve as a countermeasure to the microgravity environment by simulating gravity's response to motion. Khoshnevis had a Phase I and Phase II study to look at using resources available on the Moon or Mars to print in place large structures such as landing pads and blast walls. Bradford has had a Phase I and a Phase II to look at ways to put astronauts in a state of torpor to reduce consumables on the way to Mars. Rothschild has had two Phase I studies looking at how biomaterials could be used to recycle, grow or produce materials to be used as tools, structures or even electronics. Finally, Boland had a Phase I study to create a facility on Mars for studying the survival of terrestrial life forms.

\section{Strategic Partnerships, Communications, and Outreach}

NIAC aims to capture and inspire the ingenuity of visionaries to build the future of tomorrow. This exciting work allows NIAC to successfully engage a wide ranging, diverse global audience. NIAC's audience includes members of technical and scientific communities, independent researcher groups, government institutions, industry, academia, and the general public. NIAC has developed unique partnerships and collaborations with institutions around the U.S. that help the program expand its reach. NIAC engages educators and students with educational outreach that encourages a young audience to consider Science, Technology, Engineering, and Mathematics (STEM) careers through NIAC Fellows' innovative research. NIAC innovations have the potential to fuel economic growth, the creation of new industries, companies, jobs, products and services, and the global competitiveness of the U.S. NIAC's strategic partnerships, communications and outreach serves as a critical element of NASA's public and educational value to the nation. Below is a brief summary of each of NIAC's communications efforts

\section{A. Community}

NIAC inspires an atmosphere of innovation with its Fellows that stretches the imagination and encourages creativity. The program actively cultivates a sense of community with its Fellows. Many continue to follow up with the program alerting the team years later, of awards or notable achievements that grew from their original NIAC studies. This community has prospered and continues to grow.

\section{B. NIAC Website}

NIAC's website (www.nasa.gov/niac) is the central hub of communicating program information to the public. NIAC's online followers use this site to stay current on NIAC upcoming events, funded studies, solicitations, presentations, press releases, external media, videos, and podcasts. Each NIAC Phase I and Phase II Fellow is given a web-based research page devoted to their study. Each page includes a brief abstract, graphics and related visual media and the final report. Past NIAC Symposia have also been archived to the site via LiveStream. NIAC staff and External Council biographies are available, as well as links to other NASA Space Technology programs.

\section{Annual NIAC Symposium}

NIAC holds annual public Symposia at different locations around the United States. The primary purpose of this event is for the Phase I and Phase II Fellows to report on current research findings, progress, and discuss their future plans. Additional time is built into the event to allow the Fellows to collaborate and nurture the interdisciplinary community. Unique technologies have developed through this cross-pollination between Fellows from different scientific backgrounds and many have developed into unique 'hybrid' research. The meeting receives approximately 150 live attendees, plus approximately 5,000+ virtual participants who watch live via LiveStream. The 2016 Symposium in Raleigh, NC can be viewed at: https://livestream.com/viewnow/NIAC2016.

\section{NIAC in the News}

NIAC and its Fellows are privileged to receive extensive press coverage. Hundreds of media articles have appeared detailing NIAC Fellows' concepts, and NIAC's media footprint continues to grow each year. A small sampling of publications that routinely report on NIAC studies are: NBC News, Popular Science, The New York 
Times, The Washington Post, Space.com, AIAA Daily Launch, Aviation Week, MSNBC, Discovery News, Smithsonian Magazine, Universe Today and hundreds more at major universities, newspapers and other media outlets throughout the U.S. and abroad. For examples of news articles about NIAC projects, see: https://www.nasa.gov/content/niac-in-the-news-archive.

\section{E. NIAC Videos}

The NIAC program produces NASA 360 videos that are released via YouTube each spring. Video content is captured from the Symposia to create short, 3 minute videos with animations in collaboration with the National Institute of Aerospace (https://www.youtube.com/user/FollowNASA360). Many of these videos have gone viral with one reaching over 1 million views (https://www.youtube.com/watch?v=WCDuAiA6kX0) Many television production teams have developed extensive programming of NIAC research based on their introduction from the NASA 360 videos. For examples of NASA 360 videos that have been produced, see: https://www.nasa.gov/directorates/stmd/niac/videos.

\section{F. Radio Programming}

Additional content from Symposia are used to create radio broadcasts and podcasts for Innovation Now radio (http://www.innovationnow.us/) through the National Institute of Aerospace. Innovation Now has 352 registered stations across the U.S. representing 12.5 million daily listeners. Each broadcast gives listeners a front row seat to hear compelling stories of emerging technologies and the people behind the concepts that are shaping our future. The program airs each weekday, and new 90-second episodes explore how these innovations benefit our lives and impact our world.

Numerous NIAC Fellows have also been interviewed and aired on Planetary Radio (http://www.planetary.org/multimedia/planetary-radio/), supported by The Planetary Society. Each week, Planetary Radio visits with a scientist, engineer, project manager, astronaut, or writer who provides a unique and exciting perspective on the exploration of our solar system and beyond.

\section{G. NIAC Social Media}

Further extending NIAC's visibility to the public, NIAC concepts are routinely placed on NASA's social media sites which have a large audience of followers and subscribers. Table 6 provides a breakdown of NIAC's presence in a variety of social media.

\begin{tabular}{rll}
\hline Social Media Site & URL & Audience: February, 2017 \\
Facebook & https://www.facebook.com/NASA/ & $\mathbf{1 8 , 4 5 4 , 4 8 1 ~ l i k e s ~}$ \\
Twitter & https://twitter.com/nasa & $\mathbf{2 1 . 7 M}$ followers \\
YouTube & www.youtube.com/NASATelevision & $\mathbf{1 , 1 2 9 , 9 6 6}$ subscribers \\
Instagram & www.instagram.com/nasa/ & $\mathbf{1 9 . 3 M}$ followers \\
Pinterest & www.pinterest.com/nasa & $\mathbf{4 9 , 6 1 6}$ followers \\
\hline
\end{tabular}

Table 6. NIAC Social Media Participation

\section{H. NASA Technology Day on the Hill}

Each year, hundreds of researchers across NASA are nominated to attend NASA's Technology Day on the Hill, to introduce examples of NASA space technology development to members of Congress and staffers. This year, NIAC was honored to have two Fellows as representatives at the event: Dr. Mason Peck, Cornell, University and Dr. Marco Pavone, Stanford, University. They presented their concepts and designs with demonstrations to over 500 people who attended the full day event. Among the attendees were U.S. Senators, Representatives, the NASA Administrator and Deputy Administrator.

\section{Science \& Technology Museums}

A unique partnership has developed between NIAC and many science and technology museums around the U.S. NIAC researchers are invited to share their research with large public audiences through an educational lecture series called, From Science Fiction to Science Fact (SFSF) Participants have included the Museum of Flight, in Seattle, WA, the Museum of Natural History in Raleigh, NC and the Chicago Museum of Science and Industry (MSI) in Chicago, IL.

At MSI, the event is hosted in the OMNIMAX theater where NIAC Fellows introduce their STEM related innovations to a general public audience of $~ 300-500$ youth, underrepresented students, and the general public. 
NIAC Fellows also speak with MSI's Science Minors and Science Achievers Youth Program. This youth development program provides out of school STEM learning experiences for high school aged youth from across the Chicago area. The program is designed to nurture participants in science and engineering content, to prepare them for college and to consider STEM careers. These interactions have included discussions with the Fellows about their individual career paths. NIAC looks forward to continuing this partnership to inspire the next generation of explorers and innovators.

\section{J. World Book, Inc.}

An exciting development is a new collaboration and partnership with World Book, Inc. in Chicago, IL. World Book proposes to publish a series of children's books (in print and e-book form) about applications of basic science principles in advanced space sciences. A theme in each book is the link between commonly understood science principles and the uncommon technologies to which they contribute. A feature of each title would be a capsule biography of the scientist(s) associated with a NIAC research project. The purpose of the biographies is to show that today's working adult scientist was once a school child, like the reader, who became attracted to the sciences, perhaps through books he or she read or because of an inspiring teacher, and from there, fulfilled an aspiration to become a scientist. The book series is currently in development and will be published in August, 2017.

\section{K. Mentoring}

NIAC staff mentors interns on an annual basis as well as through the NASA Girls/NASA Boys program (https://women.nasa.gov/about-nasa-girls/).

\section{Conclusion}

There have been many aerospace research and technology programs, inside NASA and around the nation, but NIAC truly is unique. While scientists and engineers are usually constrained to careful, incremental steps, this program invites researchers to be bold and imaginative. NIAC successfully communicates its cutting edge technology research with the public, educators, and students as well as developing unique strategic partnerships and collaborations. These efforts provide opportunities to change aerospace conversations, expand NASA's vision, inspire STEM, participate in NASA's Mission, foster innovation and contribute to a strong national economy. NIAC is helping to excite the general public, and inspire the next generation to dream and dare ever further.

\section{Acknowledgments}

Two of us would like to thank NASA for the funding provided to enable us to continue to support this exciting program, through NASA contracts issued to Bryce Space and Technology, (KR) and NTT Data via a subcontract to Analytic Services Inc (RT).

\section{References}

${ }^{1}$ R. Turner, J. Falker, J. Derleth, K. Reilly, "NASA Innovative Advanced Concepts,", AIAA Space 2013 Conference and Exposition, AIAA 2013-5376, Sept 2013

2 NASA Institute for Advanced Concepts, Annual Report (8th; 2005-2006), Atlanta, Ga., 2006, (http://www.niac.usra.edu/files/library/annual_report/2006annualreport.pdf) 2007.

${ }^{3}$ National Research Council. Fostering Visions for the Future: A Review of the NASA Institute for Advanced Concepts. Washington, DC: The National Academies Press, 2009 